\title{
A retrospective study of 100 cases of Eclampsia: perinatal outcomes
}

\author{
Avani Kannar, Manthan Patel*, Shetal Prajapati, Dolly Chavda
}

Department of Obstetrics and Gynecology, P.D.U. Medical College, Rajkot, Gujarat, India

Received: 28 August 2016

Accepted: 27 September 2016

\author{
*Correspondence: \\ Dr. Manthan Patel, \\ E-mail: drmanthanpatel111@gmail.com
}

Copyright: ( ) the author(s), publisher and licensee Medip Academy. This is an open-access article distributed under the terms of the Creative Commons Attribution Non-Commercial License, which permits unrestricted non-commercial use, distribution, and reproduction in any medium, provided the original work is properly cited.

\begin{abstract}
Background: Eclampsia is associated with devastating maternal and foetal complications. Eclampsia is a major cause of maternal morbidity and mortality in developing countries. Evaluation of factors contributing to occurrence of eclampsia and death of eclamptic mother is of paramount importance. The aim of the study was to determine the perinatal mortality rate in eclamptic women. To assess the perinatal outcome with respect to time between first convulsion and delivery, time of treatment and delivery .To assess the perinatal outcome and mode of delivery. In this study we have tried to know the relationship between maternal blood group and eclampsia.

Methods: A retrospective study of 100 cases of eclampsia was done in P.D.U. Medical College, Rajkot. Pregnant woman diagnosed as eclampsia during this period were included. The events and outcome of mother and fetus were recorded and analyzed.

Results: Around $60 \%$ of patients were primipara and $70 \%$ patients were from rural area. On evaluation of background characteristics, 65 patients were not booked, $48 \%$ patients were hypertensive and $40 \%$ were normotensive. Out of 14 maternal deaths, five had cerebral haemorrhage, 3 had pulmonary edema, 3 had renal failure and 2 developed PPH.

Conclusions: Majority of the patients were unbooked and young and primigravida. Fifteen percent of eclamptic women required cesarean delivery. Most common cause for neonatal death was prematurity and its attendant complications.
\end{abstract}

Keywords: Eclampsia, Edema, Preeclampsia, Primigravida

\section{INTRODUCTION}

Eclampsia is the occurrence of convulsion in a pregnant woman with preeclampsia. Eclampsia is a preventable complication of preeclampsia. Eclampsia is defined as the development of convulsions and/or unexplained coma during pregnancy or postpartum in patients with signs and symptoms of preeclampsia. Eclampsia is associated with serious maternal and perinatal complications.

Incidence of eclampsia varies between developing countries and developed countries. Though rare in developed countries incidence of eclampsia is not uncommon in India. Maternal death associated with hypertensive disorder of pregnancy contributes $10 \%$ of maternal death (Khan KS 2006 WHO). ${ }^{1}$ Globally eclampsia is the fourth most common cause of maternal death, accounting for $12 \%$ of maternal mortalities. ${ }^{2}$ The incidence of eclampsia in developed countries range from 1 in 2000 to 1 in 3448 pregnancies which is much lower than in developing countries like India. The incidence of eclampsia in India has been quoted as $1.56 \% .^{2}$ Majority of cases of eclampsia are young primigravidas and those with no prior antenatal care.

Eclampsia is still a major cause of maternal death in India (24.09\%, FOGSI study). ${ }^{3}$ Preeclampsia with its complications is responsible for $15.8 \%$ of maternal deaths in tertiary care centre in Gujarat. ${ }^{4}$ It is essential to know the demographic background of women suffering from eclampsia, complication associated with eclampsia and factors influencing maternal and fetal outcome in order to 
formulate effective strategy for reducing the number of cases of eclampsia and for improving outcome of mother and foetuses in eclampsia.

Though not all cases of eclampsia can be prevented, majority of cases can be prevented by early detection and effective treatment of preeclampsia, for which good ANC services are needed.

The objectives of this study were as following.

1. To evaluate the maternal outcome.

2. To document and analyze the demographic background of eclamptic women.

3. Evaluation of factors contributing to occurrence of eclampsia and death of eclamptic mother.

\section{METHODS}

This retrospective study of 100 cases was conducted in Obstetrics and Gynecology Department, P.D.U. Medical College Rajkot, India during Jan 2015 to July 2016. The present study aims to determine the factors affecting the maternal and perinatal outcome of eclamptic mothers. Women with other causes of convulsions were excluded.

Inclusion criteria was the patients developing eclampsia in second half of pregnancy or within ten days after delivery; and exclusion criteria was patients with convulsion due to epilepsy, cerebral cause, malaria or any other metabolic cause and patients presenting ten days or more after delivery.

Data were collected from records of labour room and Caesarean section operation theatre.

Magnesium sulphate was used to control convulsion as per Pritchard regimen in all cases.

\section{RESULTS}

Table 1: Demographic profile of patients in present study.

\begin{tabular}{|l|l|}
\hline Age group & Number of patients $(\mathbf{N}=\mathbf{1 0 0})$ \\
\hline$<21$ & 23 \\
\hline $21-30$ & 67 \\
\hline$>30$ & 10 \\
\hline Parity & \\
\hline Primi & 59 \\
\hline Multipara & 41 \\
\hline Residence & \\
\hline Urban & 30 \\
\hline Rural & 70 \\
\hline
\end{tabular}

Out of 100 eclamptic mothers in study, majority belongs to 21-20 age group, 23 patients belongs to $<21$ years. Around $60 \%$ of patients were primipara and $70 \%$ patients were from rural area.
Table 2: Background characteristics of eclamptic patients.

\begin{tabular}{|ll|}
\hline Booking status & Variable $\mathbf{N}=\mathbf{1 0 0}$ \\
\hline Booked & 35 \\
\hline Not booked & 65 \\
\hline Antenatal BP & \\
\hline Normotensive & 40 \\
\hline Hypertensive & 48 \\
\hline Not known & 12 \\
\hline Antenatal proteinuria & \\
\hline Present & 33 \\
\hline Absent & 36 \\
\hline Not known & 31 \\
\hline Gestational age & \\
\hline Preterm & 72 \\
\hline Term & 28 \\
\hline Occurrence of fits (seizures) & \\
\hline Antepartum & 73 \\
\hline Intrapartum & 09 \\
\hline Postpartum & 18 \\
\hline
\end{tabular}

On evaluation of background characteristics, 65 patients were not booked, $48 \%$ patients were hypertensive and $40 \%$ were normotensive. $33 \%$ patients had antenatal proteinuria and in $31 \%$ patient's proteinuria was not checked. Around 3 out of 4 patients in our study were preterm. Occurrence of fits in antenatal, intranatal and postpartum period was $73 \%, 09 \%$ and $18 \%$ respectively.

Table 3: Maternal complications in present study.

\begin{tabular}{|ll|}
\hline Complications & Frequency \\
\hline Acute renal failure & 13 \\
\hline Maternal stroke & 16 \\
\hline DIC & 09 \\
\hline Pulmonary oedema & 11 \\
\hline HELLP syndrome & 19 \\
\hline Abruptio placenta & 02 \\
\hline
\end{tabular}

Table 4: Perinatal outcome in eclampsia.

\begin{tabular}{|c|c|}
\hline Perinatal outcome & Frequency \\
\hline Live birth & 68 \\
\hline Still birth & 27 \\
\hline Undelivered & 05 \\
\hline \multicolumn{2}{|l|}{ Birth weight } \\
\hline Low birth weight $<2.5$ K.G. & 67 \\
\hline Normal birth weight $>2.5$ K.G. & 33 \\
\hline \multicolumn{2}{|l|}{ Maternal outcome } \\
\hline Alive & 86 \\
\hline Dead & 14 \\
\hline \multicolumn{2}{|l|}{ Mode of delivery } \\
\hline vaginal & 80 \\
\hline C- section & 15 \\
\hline undelivered & 05 \\
\hline
\end{tabular}


Nineteen patients developed HELLP syndrome, 16 had stroke and 13 had acute renal failure. Pulmonary edema was observed in 11 patients in present study. Only two patients had abruption placentae with eclampsia (Table 3).

$68 \%$ live births, $27 \%$ still births observed during the study. $67 \%$ of neonates had low birth weight. Fourteen maternal births observed during study. $80 \%$ patients delivered vaginally and 15 patients require $\mathrm{C}$-section (Table 4).

Table 5: Causes of maternal mortality in eclampsia.

\begin{tabular}{|ll|}
\hline Cause of death & Percentage \\
\hline Cerebral hemorrhage & 05 \\
\hline Pulmonary edema & 03 \\
\hline Acute renal failure & 03 \\
\hline PPH with shock & 02 \\
\hline Cardiac failure & 01 \\
\hline Total & 14 \\
\hline
\end{tabular}

Out of 14 maternal deaths, five had cerebral haemorrhage, 3 had pulmonary edema, 3 had renal failure and 2 developed PPH.

Table 6: Relationship between blood pressure and perinatal outcome.

\begin{tabular}{|c|c|c|}
\hline & No. of patients & Perinatal deaths \\
\hline $\begin{array}{l}\text { Systolic bp } \\
\geq 160 \mathrm{~mm} \text { of hg }\end{array}$ & 58 & 18 \\
\hline $\begin{array}{l}\text { Systolic bp } \\
<160 \mathrm{~mm} \text { of hg }\end{array}$ & 42 & 08 \\
\hline $\begin{array}{l}\text { Diastolic bp } \\
\geq 110 \mathrm{~mm} \text { of } \mathrm{hg}\end{array}$ & 56 & 16 \\
\hline $\begin{array}{l}\text { Diastolic bp } \\
<110 \mathrm{~mm} \text { of } \mathrm{hg}\end{array}$ & 44 & 07 \\
\hline
\end{tabular}

\section{DISCUSSION}

Eclampsia is a devastating complication of pregnancy. It is life threatening to the mother and the foetus. In the western countries the incidence of eclampsia has fallen due to the improved antenatal care. However the incidence of eclampsia is still high in the subcontinent. Since preeclampsia is known to recur it makes it all the more important to give the best possible obstetric management in the available settings. This study was done in the view to identify certain factors which could help in improving the perinatal outcome in eclampsia.

Majority were nulliparous (59\%) and in the age group less than 30 years (90\%). $72 \%$ eclampsia cases occurred in women at 36 weeks of gestation or lesser. Amongst the women with eclampsia, 67 patients delivered babies with birth weights $<2.5 \mathrm{~kg}$ and 33 with birth weights $>2.5 \mathrm{~kg}$. Thus the average birth weight was $1.825 \mathrm{~kg}$ which is much lower than the overall average of $2.6 \mathrm{~kg}$ over the same duration. Low birth weight baby is common among eclamptic mothers.

Majority of the patients were unbooked patients and did not have regular antenatal care. This indicates that a lack of awareness regarding the antenatal care was there in these patients. $74.48 \%$ were primigravida. This is similar to the other studies. ${ }^{5-7}$

The perinatal outcome was poor in those babies who were less than $2 \mathrm{kgs}$. This has not shown to correlate in another study. ${ }^{9}$ However perinatal deaths were less in those babies whose weight was above $2.5 \mathrm{kgs}$. Perinatal deaths were least in those patients who delivered within 6 hours of the first convulsion. This emphasizes the importance of swift and prompt management of these cases. It also helps the obstetrician to decide the mode of delivery. This shows that those patients who delivered within 6 hours of starting the treatment had a better perinatal outcome than those who delivered after 12 hours. This also emphasizes the importance of early delivery. Early delivery has been shown to correlate with reduced perinatal mortality in other studies. ${ }^{9}$

Perinatal deaths have been seen to be higher in those patients who had a urine albumin more than $2+$. Systolic Blood pressure of $\geq 160 \mathrm{~mm}$ of $\mathrm{Hg}$ and a diastolic blood pressure of $\geq 110 \mathrm{~mm}$ of $\mathrm{Hg}$ were associated with a higher perinatal death. Similar results have been shown in other studies. $^{9,10}$

In the recent years, caesarean section has been opted for the mode of delivery especially in salvageable babies. This has resulted in a better perinatal outcome. Other studies have reported a similar outcome with caesarean section in comparison to the vaginal route. ${ }^{11-13}$ None of the mothers experienced any major anaesthetic or surgical complications.

\section{CONCLUSION}

Majority of the patients were unbooked and young and primigravida. Fifteen percent of eclamptic women required cesarean delivery. Most common cause for neonatal death was prematurity and its attendant complications.

Perinatal mortality was high in patients who had a systolic Blood Pressure of $\geq 160 \mathrm{~mm}$ of $\mathrm{Hg}$, a diastolic Blood Pressure of $\geq 110 \mathrm{~mm}$ of $\mathrm{Hg}$, babies less than 2 kgs, urine albumin $>2+$.

Perinatal mortality was low in those patients who had delivered within 6 hours of convulsion, in patients who delivered within 6 hours of commencement of treatment, babies delivered by caesarean section and in babies above $2 \mathrm{kgs}$. 
Funding: No funding sources

Conflict of interest: None declared

Ethical approval: The study was approved by the Institutional Ethics Committee

\section{REFERENCES}

1. Khan KS, Wojdyla D, Say L, Gülmezoglu AM, Van Look PF. WHO analysis of causes of maternal death: a systematic review. Lancet. 2006;367(9516):106674.

2. Andersgaard AB, Herbst A, Johansen M. Eclampsia in Scandinavia: incidence, substandard care, and potentially preventable cases. Acta Obstet Gynecol Scand. 2006;85(8):929-36.

3. Konar H, Chakraborty AB. Maternal Mortality: A FOGSI Study (Based on Institutional Data). The Journal of Obstetrics and Gynecology of India. 2013;63(2):88-95.

4. Patel M, Goswami K, Prajapati S, Chavda D. A five years retrospective analytic study of maternal deaths at tertiary care centre, Gujarat, India. Int J Reprod Contracept Obstet Gynecol. 2016;5:2823-7.

5. Abdullah A, Shaikh AA, Jamro B. Maternal and perinatal outcome associated with eclampsia in a teaching hospital, Sukkur. Rawal Medical Journal. 2010;35(1).
6. Waarden M, Euerle B. Pre-eclampsia (Toxaemia of pregnancy). Emer Med 2003 updated April 52002.

7. Agida ET, Adeka BI, Jibril KA. Pregnancy outcome in eclamptics at the University of Abuj Teaching Hospital, Gwagwalada, Abuja: A 3 year review. Niger J Clin Pract. 2010;13(4):394-98.

8. Alam IP, Akhter S. Perinatal Outcome of Eclampsia in Dhaka Medical College Hospital, Dhaka. Bangladesh J Obstet Gynaecol. 2008;23(1):20-4.

9. Dhananjay BS, Dayananda G, Sendilkumaran D, Murthy N. A Study of factors Affecting Perinatal Mortality in Eclampsia. JPBS. 2009;22(2):2-5.

10. George IO, Jeremiah I. Perinatal Outcome of Babies Delivered to Eclamptic Mothers: A Prospective Study from a Nigerian Tertiary Hospital. International Journal of Biomedical Science. 2009;5(4):390-4.

11. Onwuhafua PI, Oguntayo A. Perinatal mortality associated with eclampsia in Kaduna, Northern Nigeria. Niger J Med. 2006;15(4):397-400.

12. Kamilya G, Barracharrya SK, Mukherji J. Changing trends in the management of eclampsia from a teaching hospital. J Indian Medical Association. 2005;103(3):132,134-35.

Cite this article as: Kannar A, Patel M, Prajapati S, Chavda D. A retrospective study of 100 cases of Eclampsia: perinatal outcomes. Int J Reprod Contracept Obstet Gynecol 2016;5:3898-3901. 